\title{
Resource availability and invasibility in an intertidal macroalgal assemblage
}

\author{
Íñigo Sánchez*, Consolación Fernández \\ Área de Ecología, Departamento de Biología de Organismos y Sistemas, Facultad de Biología, Universidad de Oviedo, \\ 33071 Oviedo, Spain
}

\begin{abstract}
The invasibility of a low intertidal macroalgal assemblage was experimentally tested from March 2003 to April 2004 at 1 locality in northern Spain. It was hypothesised that a community becomes more susceptible to invasion when there is an increase in the amount of key resources. A bifactorial ('nutrient supply' and 'macroalgal biomass removed') orthogonal experiment was designed with 3 levels in each factor (high, medium and control). Fertile plants of Sargassum muticum (Yendo) Fensholt were transplanted to each plot to simulate the arrival of an invader. The invasibility of the assemblage was quantified in the pre- (density of recruits) and post-settlement (percentage cover, size and density of $S$. muticum at the end of the experiment) phases of $S$. muticum's life cycle. Results supported the initial hypothesis. Both space availability and nutrient enrichment facilitated the establishment and spread of $S$. muticum in the experimental plots. Established $S$. muticum plants grew faster in enriched plots than in controls. Furthermore, different successional assemblages played different roles in resisting invasion as $S$. muticum's life cycle progressed. In the initial stage of the invasion, the Bifurcaria bifurcata canopy inhibited recruitment by $S$. muticum, whereas understory species did not have a significant effect on invasion success. In contrast, an increased survivorship of $S$. muticum beneath the canopy of $B$. bifurcata was observed in those plots where $S$. muticum had successfully recruited. This study shows that the invasibility of this low intertidal assemblage is mediated by a complex interaction of several resources acting at different stages during $S$. muticum's invasion.
\end{abstract}

KEY WORDS: Sargassum muticum · Invasibility · Marine invasion • Nutrients · Disturbance • Bifurcaria bifurcata $\cdot$ Macroalgal assemblage

Resale or republication not permitted without written consent of the publishe

\section{INTRODUCTION}

Some of the most important issues in invasion biology are why some native communities are more resistant to invasion than others (Huenneke et al. 1990, Lonsdale 1999, Stohlgren et al. 1999, Williamson 1999), and why some invaders become widespread and abundant when they are introduced into new areas (Keane \& Crawley 2002). Results from field studies have been inconsistent, and a general theory about community invasibility has yet to emerge (Lonsdale 1999). However, the conflicting results reported in previous studies of invasibility can be resolved in the context of the Fluctuating Resource Availability Theory (FRAT) (Davis et al. 2000). The theory argues that invading species will be more successful in those communities in which competition for resources with native species is low. That is, an increase in the availability of a limiting resource will increase the susceptibility of the community to invasion.

The predictions of FRAT have mainly been tested in studies of terrestrial plant invasions (Burke \& Grime 1996, Davis et al. 2000). In contrast, experimental studies investigating the mechanisms underlying invasion resistance in marine communities are rare (Stachowicz et al. 1999, Britton-Simmons 2003), despite the fact that marine introductions are a very common phenomenon (Carlton 1996, Verlaque 2001, Boudouresque \& Verlaque 2002). 
On a world-wide basis, space and seawater inorganic nutrients are the limiting resources for macroalgae in most temperate systems (Chapman \& Craigie 1977, Sousa 1985), and therefore, in the context of FRAT, one might expect them to have effects on the susceptibility of communities to invasion by alien species. It has been argued that disturbance facilitates invasion by reducing the abundance of competitors or by increasing resource levels (D'Antonio 1993), especially in intertidal habitats where disturbances are strong organising forces of the community structure (Dayton 1971). Nutrient availability is another important ecological factor regulating the structure of coastal macroalgal communities (Valiela et al. 1997, Benedetti-Cecchi et al. 2001), and several studies on terrestrial systems have shown its importance in determining a community's invasibility (see Davis et al. 2000). However, in spite of the growing number of studies assessing the effects of nutrient supply on algal community structure, the role of nutrient inputs on community invasibility has not been previously tested.

In the present study, we used the invasion of a low intertidal macroalgal assemblage by the brown seaweed Sargassum muticum (Yendo) Fensholt to test whether the availability of space and nutrients affects the invasibility of this assemblage. Observational (Deysher \& Norton 1982, Critchley et al. 1987) and more recent experimental studies (Andrew \& Viejo 1998, Britton-Simmons 2003) have demonstrated the important role played by disturbance in facilitating the invasion of $S$. muticum by providing cleared substrate. However, when Sargassum's reproductive period is not coincident with disturbance events, its propagules encounter native communities representing a variety of successional stages, reflecting the varied disturbance histories of different portions of the substratum. The relative invasibility of different successional stages is not understood.

By experimental manipulation of the levels of these limiting resources and by assessing the invader success after an artificial invasion, we try to understand how settlement and early development of invasive Sargassum muticum were affected by resource availability (nutrients) and the structure of macroalgal assemblages (as determined by the intensity of disturbance).

\section{MATERIALS AND METHODS}

The invader. Sargassum muticum is a native species of Japan, and was reported for the first time in England in 1973 (Farnham et al. 1973). It has subsequently spread north and southwards along the coasts of Europe (Fernández 1999, Karlsson \& Loo 1999). In
Spain it has successfully colonised shallow subtidal habitats on sheltered shores, intertidal rock pools and the low intertidal at some semi-exposed localities (Gorostiaga et al. 1988, Andrew \& Viejo 1998, Fernández 1999). S. muticum has a well-marked seasonal cycle of growth, initiated in autumn and extending to the next summer (Fernández 1999). At the end of the growth phase, the plants become fertile and a period of reproduction starts. Senescence occurs simultaneously with full maturity increasing along summer. The species is monoecious, self-fertile and highly fecund (Norton 1977, Arenas \& Fernández 1998). When fertilised embryos are released from reproductive structures (called 'receptacles') they colonise the substratum in close proximity to the parent plant (Deysher \& Norton 1982, Andrew \& Viejo 1998) and become visible in early autumn (Arenas \& Fernández 2000).

Study site. The experiment was carried out from March 2003 to April 2004 in the low intertidal (0.4 to $0.8 \mathrm{~m}$ above the lowest astronomical tides, LAT) at a locality in northern Spain, Aramar $\left(43^{\circ} 36^{\prime} \mathrm{N}, 5^{\circ} 46^{\prime} \mathrm{W}\right)$. The invasive seaweed Sargassum muticum and the native algae Gelidium spinosum (S. G. Gmelin) P. C. Silva and Bifurcaria bifurcata R. Ross codominate at this intertidal level (Sánchez et al. 2005). Aramar is a gently sloping rocky shore facing NE, located on the eastern face of Cape Peñas. This area is partially protected by reefs from the rough weather and severe storms that occur from October to April. Nutrient dynamics in this region correspond to a temperatewater model (Rico \& Fernández 1996), with the highest values during autumn-winter and the lowest in summer.

Experimental design. To test how resource availability influences the invasibility of a native intertidal algal assemblage by Sargassum muticum, we used a 2-factor (nutrients and space), fully orthogonal design, with 3 levels per resource (high, medium and control).

During the spring tides of March 2003, when nutrients were becoming scarce in seawater, 27 permanent $20 \times 20 \mathrm{~cm}$ plots within the Gelidium spinosum-Bifurcaria bifurcata-Sargassum muticum assemblage were randomly established along $200 \mathrm{~m}$ of coastline. The 3 levels of nutrient addition were randomly assigned, so that there were 9 plots for each nutrient treatment level (high, medium, control). Nutrients were left at natural levels in control plots. Within each nutrient treatment level, 3 plots were randomly assigned to the high space availability treatment, 3 were assigned to the medium space availability treatment and 3 were left unmanipulated, as controls. Therefore, there were 3 replicates in each treatment combination. The corners of the experimental quadrats were marked with plastic markers anchored to the substratum to allow repeated sampling. S. muticum plants that were inside 
and near the plots $(<5 \mathrm{~m})$ were removed, so the plots were mostly covered by a canopy dominated by $B$. bifurcata and G. spinosum.

Two mesh bags containing $2 \mathrm{~kg}$ (high enrichment, hereafter $\mathrm{HE}$ ) or $1 \mathrm{~kg}$ (medium-enrichment, hereafter $\mathrm{ME}$ ) of slow, controlled release fertiliser (Multicote ${ }^{\circledR} 4$, Haifa Chemicals) were enclosed in $30 \times 10 \times 7 \mathrm{~cm}$ fences anchored to the rock with 3 stainless steel screws on either side. The fences were located at both sides of the plots, perpendicular to the shoreline, to minimise damage during rough weather. The same procedure was used for unenriched plots (hereafter UE), except that Multicote ${ }^{\circledR}$ was omitted. We used Multicote ${ }^{\circledR}$ containing a ratio $17 \% \mathrm{~N}\left(8.5 \% \mathrm{NH}_{4}{ }^{+}, 3.7 \%\right.$ $\mathrm{NH}_{3}$ and $\left.4.8 \% \mathrm{NO}_{3}{ }^{-}\right), 17 \% \mathrm{P}\left(\mathrm{P}_{2} \mathrm{O}_{5}\right)$ and $17 \% \mathrm{~K}\left(\mathrm{~K}_{2} \mathrm{O}\right)$, thus enhancing both nitrogen and phosphorus. The mesh bags were replaced monthly.

In March 2003, space availability was manipulated to 3 levels: (1) high (100\% cover of macroalgae removed, hereafter HD), (2) medium (50\% cover of macroalgae removed, hereafter MD) and (3) control plots (unmanipulated, hereafter UD). The biomass removed was bagged and transported to the laboratory to obtain dry biomass. After this manipulation (in March 2003), the experimental plots were not disturbed again.

Direct and indirect methods to quantify nutrient enrichment. To test whether Multicote ${ }^{\circledR}$ was effective, we sampled water monthly, on incoming tides from March 2003 to April 2004, $5 \mathrm{~cm}$ above the control and enrichment plots. The water was filtered in situ through a GF/F filter into $10 \mathrm{ml}$ polyethylene tubes. The samples were transported from the shore inside an isotherm bag $\left(<4^{\circ} \mathrm{C}\right.$, in darkness) and stored at $-20^{\circ} \mathrm{C}$ in the laboratory within $1 \mathrm{~h}$ of collection. Concentrations of $\mathrm{NO}_{3}{ }^{-}, \mathrm{NO}_{2}{ }^{-}, \mathrm{NH}_{4}{ }^{+}$and $\mathrm{PO}_{4}{ }^{3-}$ were determined with a continuous flow analyser (Skalar San Plus). Despite the fact that our fertiliser did not contain $\mathrm{NO}_{2}^{-}$, previous enrichment trials showed that high concentrations of $\mathrm{NO}_{3}{ }^{-}$corresponded with $\mathrm{NO}_{2}{ }^{-}$concentrations. For this reason, the latter inorganic form was considered in the subsequent analyses.

To check indirectly if nutrients provided by diffusers were being used by the vegetation surrounding experimental plots, 3 to 5 fronds of Gelidium spinosum were collected monthly around each plot to perform thallus nutrient content analyses. We have chosen this method because of the hyperbolic relationship between tissue $\mathrm{N}$ and seawater nitrate found by Rico \& Fernández (1996) for this species. After removing all the epiphytes, G. spinosum plants were rinsed and dried for $48 \mathrm{~h}$ at $60^{\circ} \mathrm{C}$ and ground with a mixer mill (MM 200, F. Kurt Retsch) for 3 min to homogenise them. $\mathrm{C}$ and $\mathrm{N}$ thallus content were analysed with a CHN Elemental Analyser (Perkin Elmer Analytical Instruments). Ash contents were estimated after drying at $60^{\circ} \mathrm{C}$ for $48 \mathrm{~h}$ and then incinerating for $2 \mathrm{~h}$ at $450^{\circ} \mathrm{C}$. $\mathrm{C}$ and $\mathrm{N}$ thallus content are expressed as a fraction of the ash-free dry weight (AFDW).

Experimental invasion technique. The limited dispersal range of Sargassum muticum allowed us to 'artificially' invade the experimental plots. Using this technique we ensured an appropriate propagule pressure by $S$. muticum, and no significant differences on the arrival of $S$. muticum propagules among experimental plots were expected. During the spring tides of June 2003, 54 fertile plants of $S$. muticum (plants around $1 \mathrm{~m}$ in length and bearing mature receptacles) from an adjacent area were carefully detached from the substratum and a cable was firmly tied to the holdfast of each one. Two S. muticum plants were anchored in each plot, using a second cable tie attached to screws. The screws were inserted into plastic wall anchors, which had been inserted in holes drilled in the rock. A swivel was placed between the cable ties to minimise plant damage due to wave action. In August, after release of embryos, all fertile plants of $S$. muticum were removed from the plots.

Measurements of invasibility. We monitored the percentage cover of algae at the start of the experiment (before any manipulation took place), 3 mo later (June 2003, when experimental invasion was imposed), 6 mo later (September 2003, when new recruits were visible) and monthly from December 2003 to April 2004. A $20 \times 20 \mathrm{~cm}$ PVC quadrat divided by monofilament nylon fishing line into $3.8 \times 3.8 \mathrm{~cm}$ squares was used. Two layers of line were used to avoid parallax errors in sighting. Primary and secondary cover (cover of algae on the substratum and overstory canopy) was recorded at the 49 intersection points (maximum 98 points) in each plot, and the data were transformed as specific cover values. For this reason estimates of cover may sum to $>100 \%$. Macroalgae were grouped into functional form groups as described by Steneck \& Dethier (1994). Seven groups were considered: (1) Bifurcaria bifurcata, the dominant species in UD plots, (2) filamentous species, (3) foliose species, (4) corticated macrophytes, (5) leathery macrophytes (B. bifurcata excluded), (6) articulated calcareous species and (7) crustose forms.

When new Sargassum muticum juveniles (those coming from the experimental invasion imposed in June 2003) within the plots became visible to the naked eye (September 2003), they were counted. Monthly, from December 2003 until the end of the experiment, the length of these new individuals was measured. Survival of S. muticum was also calculated from differences in density between September 2003 and April 2004. In summary, recruitment was used as a metric of invasion success during the pre-settlement phase of $S$. muticum's life history, and percentage 
cover, length and density of $S$. muticum plants were used as estimates of invasion success in the postsettlement phase of the invasion.

Data analyses. A 2-way ANOVA was used to test for differences between nutrient and space availability treatments on: (1) the number of Sargassum muticum recruits (September 2003 data) and (2) the mean size of plants, plant density and percentage cover of $S$. muticum at the end of the experiment (April 2004). Both factors were considered fixed and with 3 levels each. Cochran's test was used to test data for homogeneity of variances, and, where appropriate, logarithmic transformations were applied. Normality was also tested using the Kolmogorov-Smirnov test $(\alpha=0.05)$. In all cases, differences among means after significant F-tests were analysed by Student-Newman-Keuls tests. The Spearman rank correlation procedure was used to establish whether a significant relationship occurred between the number of recruits (September 2003 data) and the survival of $S$. muticum and the percentage cover of Bifurcaria bifurcata when the experimental invasion was imposed (June 2003).

Because of the seasonal dynamics of the nutrients in the study area, we decided to perform a crude comparison of nutrient availability in experimental plots by pooling all data throughout the study period (March 2003 to April 2004). Student's $t$-tests for unpaired data were used to compare differences in seawater nutrient concentrations and in thallus nutrient contents in Gelidium spinosum plants between enriched $(\mathrm{HE}+\mathrm{ME})$ and control areas during the summer period (June to September), the period in which natural dissolved seawater nutrients are the lowest. For these analyses, data from $\mathrm{HE}$ and ME plots were pooled in order to simplify the results. When parametric assumptions were not fulfilled by the data, Mann-Whitney $U$-tests were applied. All testing was done with SPSS Version 11.0 for Windows.

To describe assemblage responses to enrichment treatments during the experiment, non-metric multi- dimensional scaling (nMDS) ordinations were performed separately for highly disturbed and undisturbed plots. In order to increase the power of the analyses we did not consider medium-disturbed plots. These analyses were based on Bray-Curtis similarity matrices derived from cover data after a square-root transformation to reduce the influence of dominant species. Because we were interested in possible changes of macroalgal structure induced by nutrient inputs (presence of nutrient inputs vs. absence), 4 groups were considered-a priori-for each nMDS analysis: HE March 2003 plots, UE March 2003 plots, HE April 2004 plots and UE April 2004 plots. Sargassum muticum was omitted from the data set to check if the possible differences between groups were caused not only by the presence of the species, but by changes in the remaining assemblage. One-way ANOSIM (on square-root-transformed cover data) was used for the null hypotheses of 'no group differences' between the 4 groups generated in each nMDS. Pairwise comparisons were also calculated. When the ANOSIM test indicated significant differences between groups, the similarity percentage procedure SIMPER was performed on the data in order to determine which species contributed most to the dissimilarity between these groups. All these calculations were performed using the PC software PRIMER 5.2.9 for Windows (Plymouth Marine Laboratory).

\section{RESULTS}

\section{Effectiveness of the treatments}

The fertilisation treatment significantly increased the nutrient concentrations surrounding the experimental plots, but with high temporal variability (Fig. 1). The average nitrate, nitrite, ammonium and phosphorous concentrations in seawater adjacent to
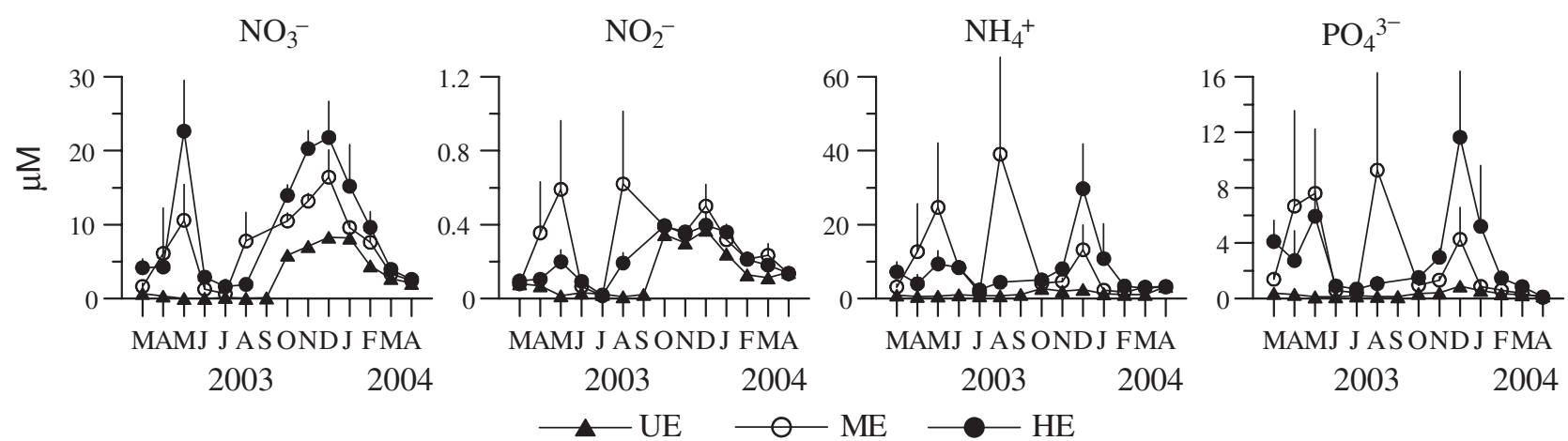

Fig. 1. Nutrient concentrations (mean $\pm \mathrm{SE}, \mathrm{n}=9$ ) around experimental plots during the study period. Nutrient enrichment treatments are indicated; note different $y$-axes between nutrients (UE: unenriched plots; ME: medium-enriched plots; HE: highly enriched plots) 
diffusers filled with Multicote ${ }^{\circledR}$ fertiliser (averaged HE and ME plots, $8.30 \pm 2.16,0.25 \pm 0.06,8.46 \pm 4.20$, $2.82 \pm 1.59$, respectively) during the course of the experiment (March 2003 to April 2004) were significantly higher than in UE plots $(2.83 \pm 0.09,0.13 \pm 0.01,1.39 \pm$ $0.14,0.31 \pm 0.03$, respectively) (Mann-Whitney $U$-tests, $\mathrm{p}<0.05$ in every case). Moreover, diffusers filled with Multicote ${ }^{\circledR}$ did not contaminate control plots: nutrient concentrations in control plots were similar to those found in the study area (Rico \& Fernández 1996). Nutrient enhancement affected the nitrogen content of Gelidium spinosum (Fig. 2) during summer (June to September). Thallus nitrogen content differed between treatments (UE mean $=1.33 \pm 0.06 \%$ [SE] and nutrient-enhanced mean $=1.93 \pm 0.06 \%$ [SE], $t=6.91$, $\mathrm{p} \ll 0.05$ ), but no differences were found in thallus carbon content (UE mean $=35.91 \pm 0.32 \%$ and nutrientenhanced mean $=36.54 \pm 0.18 \%, t=1.79, \mathrm{p}>0.05)$.

The mean $( \pm \mathrm{SE})$ macroalgal biomass removed from HD plots in March 2003 (a range between nutrient treatments of 34.5 to 41.6 dry biomass $400 \mathrm{~cm}^{-2}$ ) was more than twice that removed from MD plots (a range between nutrient treatments of 13.3 to 18.7 dry biomass $400 \mathrm{~cm}^{-2}$ ) across all enrichment treatments.

\section{The macroalgal assemblage}

During the period when experimental invasion was imposed (June 2003) UD plots were dominated by Bifurcaria bifurcata, while HD plots were colonised by a dense coverage of understory species belonging mainly to filamentous [Ceramium spp., Cladostephus spongiosus (Hudson) C. Agardh, Stypocaulon scoparium (Linnaeus) Kützing] and foliose (Ulva spp.) functional groups. MD plots were a mixture of both understory species and B. bifurcata (Fig. 3).

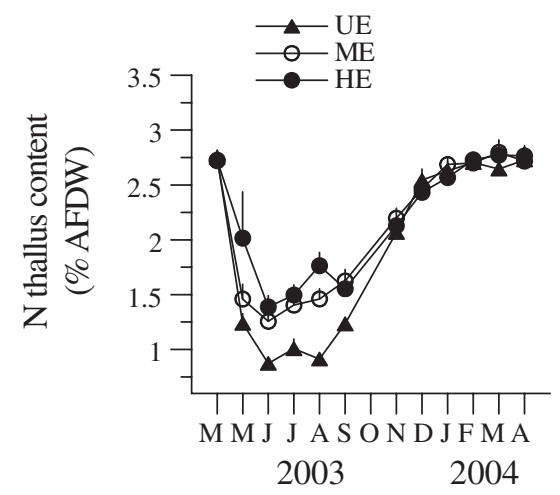

Fig. 2. Gelidium spinosum. Variation in thallus nitrogen content ( $\%$ ash-free dry weight, AFDW) during the study period (mean $\pm \mathrm{SE}, \mathrm{n}=9$ ). Nutrient enrichment treatments are indicated (abbreviations as in Fig. 1)

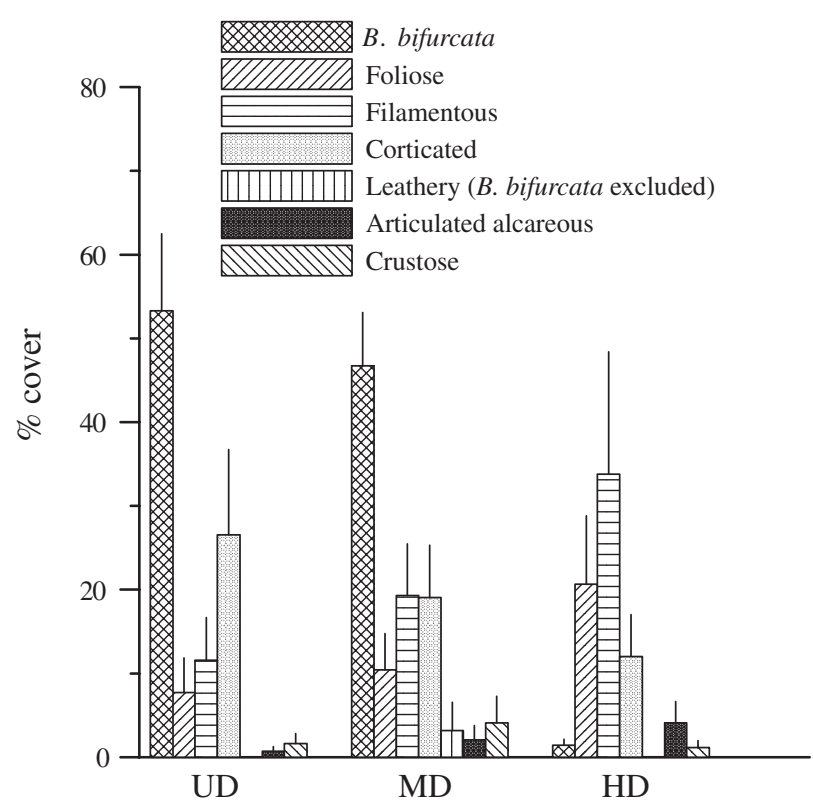

Fig. 3. Percentage of cover (mean $\pm \mathrm{SE}, \mathrm{n}=9$ ) of macroalgal functional groups and Bifurcaria bifurcata when experimental invasion was imposed (June 2003) (UD: undisturbed plots; MD: medium-disturbed plots; HD: highly disturbed plots)

Bidimensional representation of the nMDS ordination analyses showed that there was no effect of nutrient enrichment on the native macroalgal assemblage (UD plots, Fig. 4A) or on disturbed plots (HD plots, Fig. 4B). However, significant differences were detected between time groups (March 2003 to April 2004)

HE March $2003 \quad \square$ HE April 2004
UE March $2003 \quad$ O UE April 2004

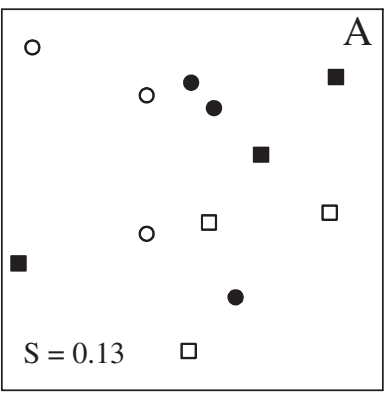

UD plots

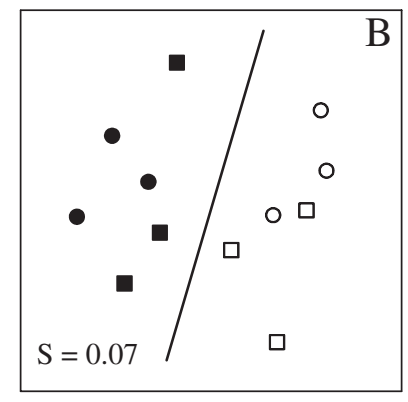

HD plots
Fig. 4. nMDS (non-parametric multi-dimensional scaling) plots on square-root-transformed macroalgal abundance data, showing temporal changes in assemblage structure from March 2003 to April 2004 for undisturbed (A) and highly disturbed plots (B) (symbols are indicated, abbreviations as in Fig. 1; S: stress) 
Table 1. Sargassum muticum. Results of ANOVA testing effects of nutrient addition and space availability on recruitment (September 2003 data). Student-Newman-Keul's test: Nutrient enrichment, $\mathrm{HE}=\mathrm{UE}>\mathrm{ME}$; Space availability, $\mathrm{HD}=\mathrm{MD}>\mathrm{UD}$

\begin{tabular}{|lrccc|}
\hline Source of variation & df & MS & $F$ & $\mathrm{p}$ \\
\hline Nutrient enrichment (N) & 2 & 0.8055 & 3.7681 & 0.0429 \\
Space availability (S) & 2 & 1.3469 & 6.3004 & 0.0084 \\
$\mathrm{~N} \times \mathrm{S}$ & 4 & 0.1586 & 0.7418 & 0.5758 \\
Error term & 18 & 0.2137 & & \\
\hline
\end{tabular}

when HD plots were considered (global $\mathrm{R}=0.65$, $\mathrm{p}<$ 0.01; Fig. 4B). Pairwise comparisons were also calculated. Because there are only 10 different permutations under the null hypotheses, the R-values are more informative than the significance level (this can never be $<10 \%$, Clarke \& Gorley 2001). In this context, the pairwise R-values give an absolute measure of how separated the groups are, on a scale of 0 (indistinguishable) to 1 (all similarities within groups are less than any similarity between groups). Following these guidelines, significant differences in assemblage structure were detected between time periods (March 2003 to April 2004), but not between nutrient treatments in each time period. Bifurcaria bifurcata (35.76\%), Stypocaulon scoparium (14.91\%) and Ulva rigida C. Agardh (9.94\%) contributed most to the observed dissimilarity between time periods in HE plots, and B. bifurcata $(21.20 \%)$, Jania rubens (Linnaeus) J. V. Lamouroux (16.40\%) and S. scoparium $(12.40 \%)$, in UE plots.
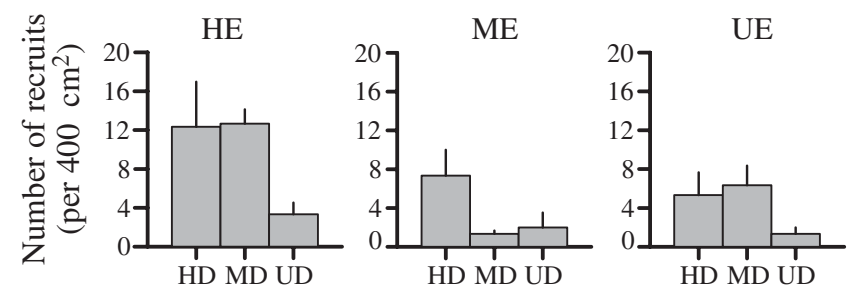

Fig. 5. Sargassum muticum. Density (mean $\pm \mathrm{SE}, \mathrm{n}=3$ ) of recruits (per $400 \mathrm{~cm}^{2}$ ) in September 2003. Different treatments are indicated (UE: unenriched plots; ME: medium-enriched plots; HE: highly enriched plots; UD: undisturbed plots; MD: medium-disturbed plots; HD: highly disturbed plots)

\section{Sargassum muticum recruitment}

Recruits (>1 cm) were first visible in September 2003 , with a range of 0 to 20 plants $400 \mathrm{~cm}^{-2}$, but they increased until March and even to April in the HE treatment (Fig. 5). This increase must have been due to growing germlings that were not visible during the first sampling dates and possibly belonged to a bank of microscopic germlings with delayed development, as Arenas et al. (2002) observed for this species. Both nutrient enhancement and space availability had significant effects on recruitment of Sargassum muticum (Fig. 5), as indicated by ANOVA (Table 1). The density of recruits was 2- or 3-fold higher in disturbed plots. These results were consistent among nutrient treatments, except in ME plots, where the number of new recruits was almost the same as in the UE plots. Likewise, the highest densities of new recruits were recorded in HE plots (Fig. 5).

\section{Sargassum muticum's post-settlement phase}

The analysis of post-settlement metrics of invasion success (percentage cover, length and density of Sargassum muticum plants) shows that communities were more susceptible to invasion when nutrient levels were increased (Fig. 6). Significant differences in the percentage cover and length of $S$. muticum plants were found between nutrient enrichment treatments at the end of the experiment, but no differences were detected between space availability treatments (Table 2).

\section{Bifurcaria bifurcata and invasibility}

The relative importance of a canopy of Bifurcaria bifurcata for invasion resistance was shown by plotting the number of recruits and survival of Sargassum muticum against percentage cover of $B$. bifurcata by the time the experimental invasion was imposed (June 2003). When data across all treatments were considered $(n=27)$, a significant negative relationship was

Table 2. Sargassum muticum. Results of ANOVA testing effects of nutrient addition and space availability on percentage of cover, length and plant density at the end of the experiment (April 2004 data). Student-Newman-Keul's test: HE > ME > UE; $\mathrm{HE}=\mathrm{ME}>\mathrm{UD}$

\begin{tabular}{|c|c|c|c|c|c|c|c|c|c|c|}
\hline \multirow[t]{2}{*}{ Source of variation } & \multicolumn{4}{|c|}{ Final percentage cover } & \multicolumn{3}{|c|}{ Length } & \multicolumn{3}{|c|}{ Plant density } \\
\hline & df & MS & $F$ & $\mathrm{p}$ & MS & $F$ & $\mathrm{p}$ & MS & $F$ & $\mathrm{p}$ \\
\hline Nutrient enrichment $(\mathrm{N})$ & 2 & 2250.45 & 4.93 & 0.0195 & 748.51 & 3.75 & 0.0433 & 29.48 & 3.40 & 0.0548 \\
\hline Space availability (S) & 2 & 59.69 & 0.13 & 0.8781 & 69.02 & 0.34 & 0.7119 & 14.92 & 1.72 & 0.2068 \\
\hline $\mathrm{N} \times \mathrm{S}$ & 4 & 317.22 & 0.69 & 0.6047 & 160.39 & 0.80 & 0.5381 & 11.48 & 1.32 & 0.2987 \\
\hline Error term & 18 & 455.98 & & & 199.37 & & & 8.66 & & \\
\hline
\end{tabular}



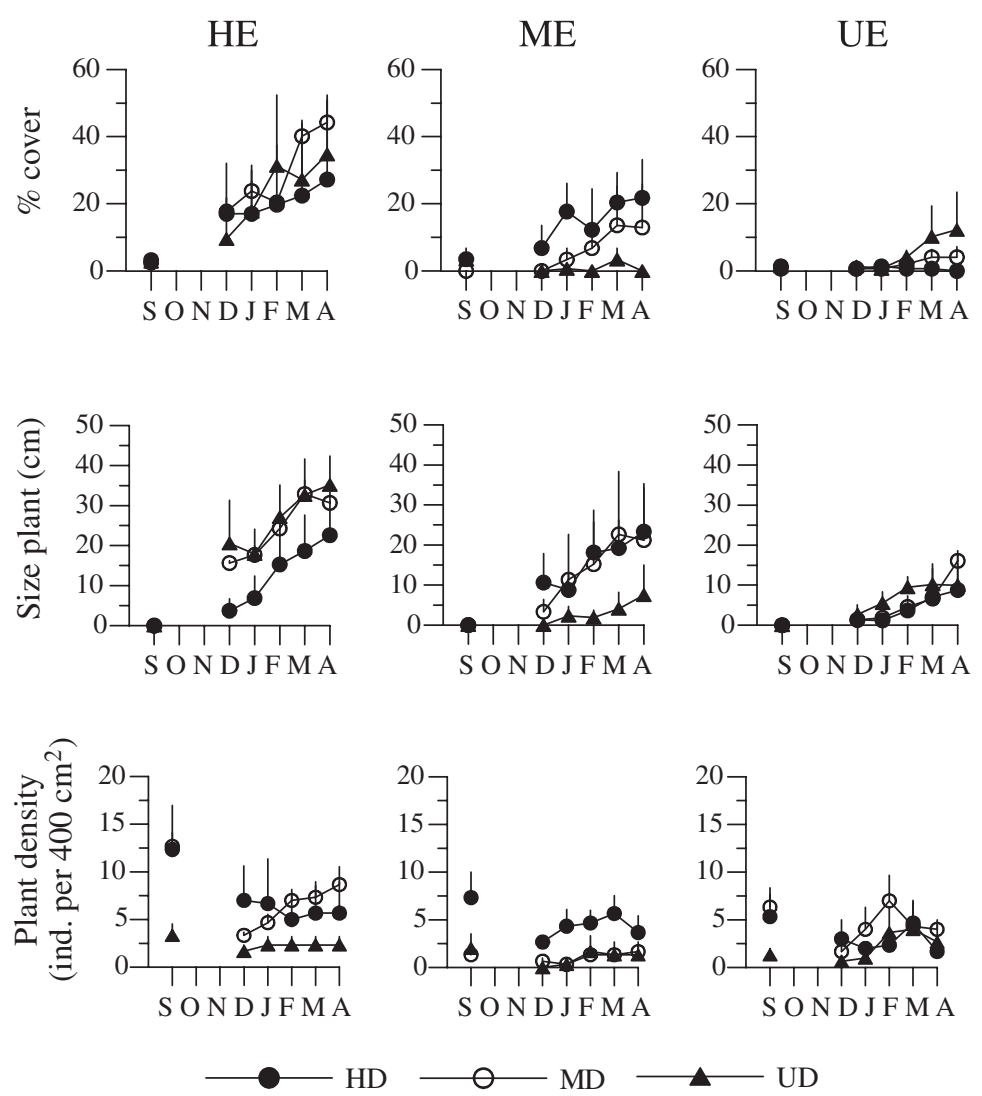

Fig. 6. Sargassum muticum. Percentage of cover, size and plant density during the course of the experiment. Values are means $( \pm S E, n=3)$. Different treatments are indicated (abbreviations as in Fig. 5)

$$
\begin{aligned}
& \text { O UE plots } \\
& \text { - E plots }
\end{aligned}
$$
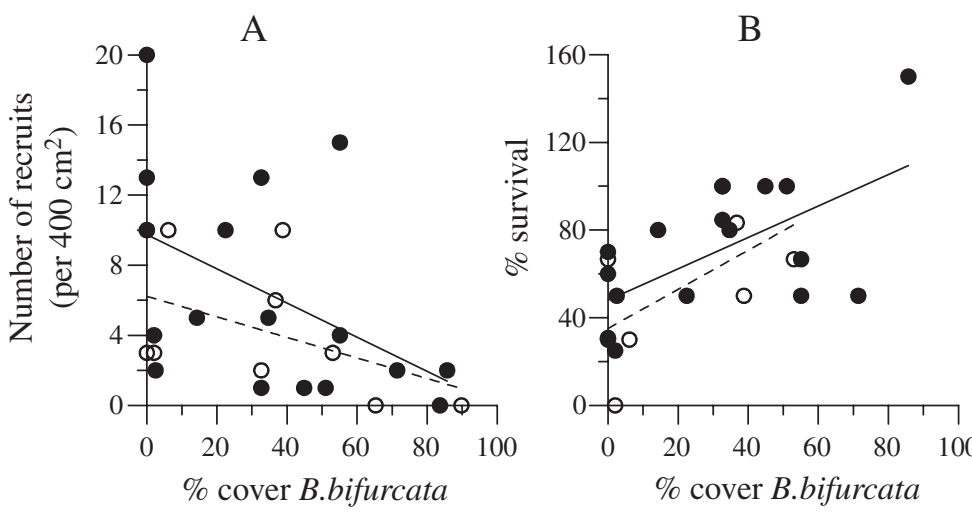

Fig. 7. Relationships between the number (A, September 2003) and percentage survival (B, April 2004) of Sargassum muticum recruits and the percentage cover of Bifurcaria bifurcata when experimental invasion was imposed (June 2003). Two UE plots in Panel B were discarded because initial density of $S$. muticum recruits was zero. Nutrient enrichment treatments are indicated (continuous line: regression line for all data; broken line: regression line for UE plots; UE: unenriched plots; E: enriched plots $[\mathrm{ME}+\mathrm{HE}])$ observed $\left(\mathrm{r}_{\mathrm{s}}=-0.551, \mathrm{p}<0.01\right)$; similar results were obtained when only UE plots were considered $(n=9)\left(r_{s}=-0.445, p<\right.$ 0.05) (Fig. 7A). In contrast, a significant positive correlation was found between percentage of survival of $S$. muticum and $B$. bifurcata percentage cover $\left(\mathrm{r}_{\mathrm{s}}=0.445, \mathrm{p}<\right.$ $0.05)$ when all data were included in the analysis. Finally, no pattern was observed using the UE subset of plots $\left(\mathrm{r}_{\mathrm{s}}=0.531\right.$; $\mathrm{p}>0.05$ ) (Fig. 7B).

\section{DISCUSSION}

The importance of disturbances in facilitating the establishment of Sargassum muticum is well known (Viejo 1997, Andrew \& Viejo 1998). Free available space seems to be one of the main constraints of $S$. muticum invasions (DeWreede 1983, Andrew \& Viejo 1998, Stæhr et al. 2000), especially in those habitats with low levels of natural disturbance (Britton-Simmons 2003). In addition, the timing of disturbance-relative to propagule availability - is important for predicting the success of an invasion (Kenelly \& Larkum 1983, Benedetti-Cecchi \& Cinelli 1994). Since our removal treatments were not carried out during $S$. muticum's reproductive period we were able to test the relative importance of canopy (Bifurcaria bifurcata) and understory species for biotic resistance and determine at what point in the invasion process (i.e. pre- and postsettlement phases of the invasion) these groups played an important role. In the initial stage of the invasion, a $B$. bifurcata canopy inhibited successful recruitment by S. muticum. In contrast, another important functional component of the assemblage, understory species (mainly filamentous and foliose species), were less important in resisting S. muticum establishment. Although other experimental and observational studies have suggested the importance of a canopy to avoid $S$. muticum recruitment (Deysher \& Norton 1982, DeWreede 1983, Andrew \& Viejo 1998, Britton-Simmons 2003), it is not yet clear whether there is a general mechanism underlying this phenomenon. Other factors, like low levels of light beneath the canopy (DeWreede 1983, Andrew \& Viejo 1998, Britton-Simmons 2003), sedimentation (Vadas et al. 1992) 
and/or herbivory by canopy-associated herbivores (Hawkins \& Hartnoll 1983) may also reduce survivorship of $S$. muticum. The mechanisms that prevent the establishment of $S$. muticum in a mature community must therefore be identified to gain a more comprehensive understanding of invasion resistance by canopy algae.

After settlement, a dense canopy seems to be a good environment that enhances survivorship of Sargassum muticum recruits, probably due to the limited air exposure the species supports (Norton 1977). In spite of the low density of recruits (visible to the naked eye) observed beneath the canopy of Bifurcaria bifurcata, the few that were able to reach it showed the highest rates of survivorship, while juvenile plants growing in plots dominated by understory species showed high mortality rates. Britton-Simmons (2003) reported that in a subtidal macroalgal community in Washington State, resistance to the Japanese seaweed $S$. muticum arose, because different functional groups within the community pre-empted key limiting resources in different stages of the invasion. A similar mechanism appears to be operating in our system. In light of these results, it is critically important to examine as much of the life cycle of the invader as possible, because different resources may be important at different stages of the invasion (Britton-Simmons 2003).

As predicted by FRAT (Davis et al. 2000), nutrient supply during the post-settlement phase of Sargassum muticum was the key factor controlling community invasibility. Laboratory experiments with 2 co-generic Fucus species, the invasive Fucus evanescens C. Agardh and the native Fucus vesiculosus Linnaeus (Steen \& Scrosati 2004), have shown the same results: the invader was favoured when nutrient levels were increased. Although several field studies in terrestrial communities have produced similar results (Huenneke et al. 1990, Burke \& Grime 1996), this is the first explicit evaluation of this phenomenon in a marine system. However, as pointed out by several authors (Davis et al. 2000), the basic processes operating through the natural expansion of native species are essentially the same as those that facilitate the spread of exotics. In this way, previous studies about the effects of nutrient supply on native communities are in agreement with our results: nutrient pulses may have significant impacts on macroalgal communities by favouring fastgrowing species to the detriment of canopy-forming species (Sand-Jensen \& Borum 1991, Duarte 1995, Worm \& Sommer 2000). Understanding these natural processes is also a key to unravelling the mechanisms underlying the causes and consequences of invasions and to make better predictions of the spatial and temporal scales of their occurrence.

The duration of the nutrient pulses can strongly influence the response of the seaweeds, and, for this reason, the monitoring of nutrient levels through time is considered indispensable for the interpretation of nutrient enrichment studies (Worm et al. 2000). However, the difficulty of collecting water surrounding diffusers (i.e. heavy swells in winter), lack of information about field release rates of the fertiliser, and time limitations in sampling have inhibited the development of field enrichment experiments on intertidal habitats. Few studies have attempted to quantify directly in the field the effectiveness of the nutrient enrichment treatments through time in a rocky intertidal habitat, with some notable exceptions (Wootton et al. 1996, Pfister \& Van Alstyne 2003). However, the results of the experiment (direct and indirect measures of enrichment) show the difficulty in creating or measuring a gradient of nutrients in the field.

Previous studies of benthic response to nutrient enrichment have shown that an increase in nutrient levels is followed by a change in the composition and structure of assemblages (Sand-Jensen \& Borum 1991, Wootton 1991, Duarte 1995, Valiela et al. 1997) from canopy-forming to opportunistic communities (Duarte 1995, Pedersen \& Borum 1996). However, recent evidence has shown that well-established communities were not affected by eutrophication and that only cleared areas were modified by nutrient inputs (Bokn et al. 2003). In our case, the increase of nutrients over a $1 \mathrm{yr}$ period did not exert any effect on the structure of the assemblage. The only conspicuous changes were detected in perturbed plots, between the start and the end of the experiment, as a result of the succession process started in March 2003.

In summary, this study illustrates that the invasibility of this low intertidal assemblage is mediated by a complex interaction of several resources acting at different stages during the invasion of Sargassum muticum. For a more thorough understanding of the factors controlling invasion success, experimental studies need to take into account the requirements of each invader throughout its entire life history, as well as the fluctuation in community resources within the invaded system. Finally, our results also highlight the need for a better understanding of community invasibility in marine systems, since most information to date has been obtained from terrestrial studies.

Acknowledgements. We are grateful to E. Cabal and L. Blanco for help in the field. K. Britton-Simmons, B. DíazCaneja and J. Arrontes made helpful comments on the manuscript. Thanks to G. Hernández-Carmona for discussions about the enrichment methodology. K. Britton-Simmons and J. M. Rico are thanked for editing the English. During the course of this study I.S. was funded by a FICYT pre-doctoral fellowship from the Asturias Regional Government. This study was supported by the ALIENS project (EVK3-CT200100062) of the European Union. 


\section{LITERATURE CITED}

Andrew NL, Viejo RM (1998) Effects of wave exposure and intraspecific density on the growth and survivorship of Sargassum muticum (Sargassaceae: Phaeophyta). Eur J Phycol 33:251-258

Arenas F, Fernández C (1998) Ecology of Sargassum muticum (Phaeophyta) of the north coast of Spain. III. Reproductive ecology. Bot Mar 41:209-216

Arenas F, Fernández C (2000) Size structure and dynamics in a population of Sargassum muticum (Phaeophyceae). J Phycol 36:1012-1020

Arenas F, Viejo RM, Fernández C (2002) Density-dependent regulation in an invasive seaweed: responses at plant and modular levels. J Ecol 90:820-829

Benedetti-Cecchi L, Cinelli F (1994) Recovery of patches in an assemblage of geniculate coralline algae: variability at different successional stages. Mar Ecol Prog Ser 110:9-18

Benedetti-Cecchi L, Pannacciulli F, Bulleri F, Moschella PS, Airoldi L, Relini G, Cinelli F (2001) Predicting the consequences of anthropogenic disturbance: largescale effects of loss of canopy algae on rocky shores. Mar Ecol Prog Ser 214:137-150

Bokn TL, Duarte CM, Pedersen MF, Marba N and 14 others (2003) The response of experimental rocky shore communities to nutrient additions. Ecosystems 6:577-594

Boudouresque CF, Verlaque M (2002) Biological pollution in the Mediterranean Sea: invasive versus introduced macrophytes. Mar Pollut Bull 44:32-38

Britton-Simmons KH (2003) Establishment, spread, and impact of the introduced Japanese seaweed, Sargassum muticum, in the San Juan Islands, WA. PhD thesis, University of Chicago, Chicago, IL

Burke MJW, Grime JP (1996) An experimental study of plant community invasibility. Ecology 77:776-790

Carlton JT (1996) Pattern, process, and prediction in marine invasion ecology. Biol Conserv 78:97-106

Chapman ARO, Craigie JS (1977) Seasonal growth in Laminaria longicruris: relations with dissolved inorganic nutrients and internal reserves of nitrogen. Mar Biol 40: 197-205

Clarke KR, Gorley RN (2001) PRIMER v5: user manual/ tutorial. PRIMER-E, Plymouth

Critchley AT, Nienhuis PH, Verschuure K (1987) Presence and development of populations of the introduced brown alga Sargassum muticum in the southwest Netherlands. Hydrobiologia 151/152:245-255

D'Antonio CM (1993) Mechanisms controlling invasion of coastal plant communities by the alien succulent Carpobrotus edulis. Ecology 74(1):83-95

Davis MA, Grime JP, Thompson K (2000) Fluctuating resources in plant communities: a general theory of invasibility. J Ecol 88:528-534

Dayton PK (1971) Competition, disturbance, and community organization: the provision and subsequent utilization of space in a rocky intertidal community. Ecol Monogr 41: 351-389

DeWreede RE (1983) Sargassum muticum (Fucales, Phaeophyta): regrowth and interaction with Rhodomela larix (Ceramiales, Rhodophyta). Phycologia 22(2):153-160

Deysher L, Norton R (1982) Dispersal and colonization in Sargassum muticum (Yendo) Fensholt. J Exp Mar Biol Ecol 56:179-185

Duarte CM (1995) Submerged aquatic vegetation in relation to different nutrient regimes. Ophelia 41:87-112

Farnham WF, Fletcher RL, Irvine LM (1973) Attached Sargassum found in Britain. Nature 243:231-232
Fernández C (1999) Ecology of Sargassum muticum (Phaeophyta) on the north coast of Spain. IV. Sequence of colonization on a shore. Bot Mar 42:553-562

Gorostiaga JM, Casares C, Fernández JA, Pérez B, Sarasua A (1988) Sobre la expansión de Sargassum muticum (Yendo) Fensholt en la costa Atlántica Europea. Lurralde 11: 437-443

Hawkins SJ, Hartnoll RG (1983) Grazing of intertidal algae by marine invertebrates. Oceanogr Mar Biol Annu Rev 21: $195-282$

Huenneke LF, Hamburg SP, Koide R, Mooney HA, Vitousek PM (1990) Effects of soil resources on plant invasion and community structure in Californian serpentine grassland. Ecology 71:478-491

Karlsson J, Loo LO (1999) On the distribution and the continuous expansion of the Japanese seaweed-Sargassum muticum-in Sweden. Bot Mar 42:285-294

Keane RM, Crawley MJ (2002) Exotic plant invasions and the enemy release hypothesis. Trends Ecol Evol 17(4): 164-170

Kenelly SJ, Larkum AWD (1983) A preliminary study on temporal variation in the colonization of subtidal algae in an Ecklonia radiata community. Aquat Bot 17:275-282

Lonsdale WM (1999) Global patterns of plant invasions and the concept of invasibility. Ecology 80:1522-1536

Norton TA (1977) Ecological experiments with Sargassum muticum. J Mar Biol Assoc UK 57:33-43

Pedersen MF, Borum J (1996) Nutrient control of alga growth in estuarine waters. Nutrient limitation and the importance of nitrogen requirements and nitrogen storage among phytoplankton and species of macroalgae. Mar Ecol Prog Ser 142:261-272

Pfister CA, Van Alstyne KL (2003) An experimental assessment of the effects of nutrient enhancement on the intertidal kelp Hedophyllum sessile (Laminariales, Phaeophyceae). J Phycol 39(2):285-290

Rico JM, Fernández C (1996) Seasonal nitrogen metabolism in an intertidal population of Gelidium latifolium (Gelidiaceae, Rhodophyta). Eur J Phycol 31:149-155

Sánchez I, Fernández C, Arrontes J (2005) Long-term changes in the structure of intertidal assemblages following invasion by Sargassum muticum (Phaeophyta). J Phycol 41:942-949

Sand-Jensen K, Borum J (1991) Interactions among phytoplankton, periphyton and macrophytes in temperate freshwaters and estuaries. Aquat Bot 41:137-175

Sousa WP (1985) Disturbance and match dynamics on rocky intertidal shores. In: Pickett STA, White PS (eds) The ecology of natural disturbance and patch dynamics. Academic Press, New York, p 101-124

Stachowicz JJ, Whitlatch RB, Osman RW (1999) Species diversity and invasion resistance in a marine ecosystem. Science 286:1577-1579

Stæhr PA, Pedersen MF, Thomsen MS, Wernberg T, KrauseJensen D (2000) The invasion of Sargassum muticum in Limfjorden (Denmark) and its possible impact on the indigenous macroalgal community. Mar Ecol Prog Ser 207:79-88

Steen H, Scrosati R (2004) Intraspecific competition in Fucus serratus and Fucus evanescens (Phaeophyceae: Fucales) germlings: effects of settlement density, nutrient concentration, and temperature. Mar Biol 144:61-70

Steneck RS, Dethier MN (1994) A functioning group approach to the structure of algal-dominated communities. Oikos 69:476-498

Stohlgren TJ, Binkley D, Chong GW, Kalkhan MA and 6 others (1999) Exotic plant species invade hot spots of native 
plant diversity. Ecol Monogr 69:25-46

Vadas RL, Johnson S, Norton TA (1992) Recruitment and mortality of early post-settlement stages of benthic algae. Br Phycol J 27:331-351

Valiela I, McClelland J, Hauxwell J, Behr PJ, Hersh D, Foreman K (1997) Macroalgal blooms in shallow estuaries: controls and ecophysiological and ecosystem consequences. Limnol Oceanogr 42:1105-1118

Verlaque M (2001) Checklist of the macroalgae of Thau Lagoon (Hérault, France), a hotspot of marine species introduction in Europe. Oceanol Acta 24(1):29-49

Viejo RM (1997) The effects of colonization by Sargassum muticum on tidepool macroalgal assemblages. J Mar Biol Assoc UK 77:325-340

Editorial responsibility: Otto Kinne (Editor-in-Chief), Oldendorf/Luhe, Germany
Williamson M (1999) Invasions. Ecography 22:5-12

Wootton JT (1991) Direct and indirect effects of nutrient on intertidal community structure: variable consequences of seabird guano. J Exp Mar Biol Ecol 151:139-153

Wootton JT, Power ME, Paine RT, Pfister CA (1996) Effects of productivity, consumers, competitors, and El Niño events on food chain patterns in a rocky intertidal community. Proc Natl Acad Sci USA 93:13855-13858

Worm B, Sommer U (2000) Rapid direct and indirect effects of a single nutrient pulse in a seaweed-epiphyte-grazer system. Mar Ecol Prog Ser 202:283-288

Worm B, Reusch TBH, Lotze HK (2000) In situ nutrient enrichment: methods for marine benthic ecology. Int Rev Hydrobiol 85:359-375

Submitted: May 10, 2005; Accepted: October 13, 2005

Proofs received from author(s): March 24, 2006 